\title{
NPP Unit Life Management based on Digital Twin Application
}

\author{
Alexander Arzhaev ${ }^{1, *}$, Alexey Arzhaev ${ }^{1}$, Valentin Makhanev ${ }^{1}$, Mikhail Antonov $^{2}$, Anton Emelianov ${ }^{2}$, Aleksander Kalyutik ${ }^{2}$, \\ Yury Karyakin ${ }^{2}$, Maksim Kurakin², Daniil Lyashenko², Kirill Arzhaev ${ }^{3}$, Ilya Denisov ${ }^{3}$ \\ ${ }^{1}$ LLE "SPE “DIAPROK”, Moscow, Russia Federation \\ ${ }^{2}$ Peter the Great St. Petersburg Polytechnic University, Sankt-Petersburg, Russia Federation \\ ${ }^{3}$ ANO "International Nuclear Safety Center", Moscow, Russia Federation
}

\begin{abstract}
IAEA activities on ageing management started in 1990 are a part of NPP Units life management or License Renewal as specified in national regulatory documents of member countries. Development of digital technologies makes it possible to manage lifetime NPP Unit issues in effective manner by application of Digital Twin.
\end{abstract}

Keywords. NPP Life Cycle Management, NPP systems, structures, components, ageing management, NPP Unit Digital Twin, long-term operation, NPP decommissioning.

\section{Introduction}

Optimization of technical and economic indicators of operation of new NPP units during long-term operation can be achieved on the basis of methodological approaches to Life Time Management (LTM) [1], systematized based on the results of NPP operation feedback in the IAEA member countries [2-3].

The use of Digital twins - DT for the NPP LTM unit is considered as a development of the approaches presented in [4] in relation to long-term operation conditions.

The NPP LTM is inseparably linked to ensuring safe and cost-effective long-term operation for a period of more than 45-60 years for almost all NPP units of the Russian Federation [5]: for new units in accordance with the design documentation, for existing units - in accordance with the procedures of service life extension.

\section{LTM and ageing aspects}

Correlation between LTM and ageing management is shown schematically on Fig. 1 taking into consideration the key role of systems, structures and components (SSC) integrity [6].

Lifetime management, Fig. 1, means the integration of ageing management and economic planning for NPP in order:

- to optimise the operation, the maintenance and the lifetime of the plant,

- maintain an accepted level of safety and performance,

- maximise return on investment over the lifetime of the plant.

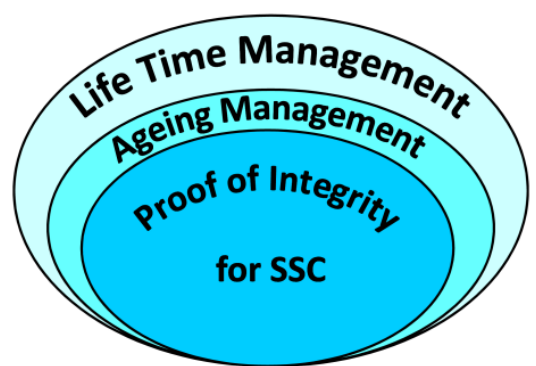

Fig.1. The relationship between the processes of the LTM, ageing management and proof of integrity for SSC

Ageing means the time-dependent gradual change of features and properties related to their function with regard to:

- the conceptual aspects (modification of requirements, modification of safety philosophy),

- the engineering aspects (mechanical SSC, buildings, electrical equipment),

- the systems and control devices relevant to NPP operation (including obsolescence of NPP I\&C systems electronic components),

- the technical specifications and the documents,

- requirements and training of NPP personnel.

This also takes into consideration the development of the state-of-the-art of science and technology. It is possible that conceptual design and engineering methods as well as administration rules may become obsolete compared to the state-of-the-art.

Ageing management, Fig. 1, covers all engineering and organisational actions for the utility to guarantee safe operation during the lifetime including control of possible ageing degradation.

Recommendations on modern approaches to accounting for the effects of aging on SSC damage during operation (aging degradation) are contained in the IAEA documents [7-9].

\footnotetext{
* Corresponding author: arzhaev.alexander@yandex.ru
} 
The issues of ensuring the structural integrity of passive elements - equipment and piping - are considered in the report [10].

\section{Possible DT types}

Depending on the range of tasks to be solved within the framework of the NPP LTM, it is possible to create and apply DTs at different levels.

One of the integrated DT options for NPPs is an automated enterprise management system of ERP class, the implementation of which is a complex one, taking into account the involvement of economic issues that are extremely sensitive for the NPP and utility management. Within the framework of the task [11], the technical requirements for the development of an automated control system for one of the new NPP unit is presented.

The implementation of Rosatom state Corporation's work on an industry-specific project for managing the NPP construction cost TCM NC (Total Cost Management Nuclear Construction) has prospects of creating a DT of the NPP unit as stated in [12].

The NPP operation Template has the Central place in the General scheme of the DT integration Figure 2 [12].

As can be seen from Fig. 2, the Maintenance automated control system (MACS) is a part of the NPP operation Template.

The possibilities of creating an NPP engineering radiation model are described in [13] and schematically presented in Fig. 3.

\begin{tabular}{|c|c|c|c|}
$\begin{array}{c}\text { Capital construction, } \\
\text { modernization, } \\
\text { life extension }\end{array}$ & $\begin{array}{c}\text { Supply and } \\
\text { contract } \\
\text { management }\end{array}$ & $\begin{array}{c}\text { Monitoring, } \\
\text { Crisis center } \\
\text { systems, } \\
\text { dispatch center, } \\
\text { cybersecurity }\end{array}$
\end{tabular}

Fig.2. The functional composition of "NPP operation

Template" (two areas highlighted in blue present finished product)
The use of similar technologies (as laser scanning, spherical photography, etc.) for forming the "as built" NPP model during construction was proposed in 2014 [14], but had no practical implementation during the construction and commissioning of VVER-1200 units of Novovoronezh NPP-2 and Leningrad NPP-2.

\section{Areas for current DT application}

Rosatom state Corporation has announced about the start of the design work for two sites: Leningrad-2 (units 3 and 4 with VVER-1200) and Smolensk-2 with VVERTOI [15]. So it seems valuable to include in design documentation generic DT development for NPP units at sites mentioned above.

Development of engineering model "as built" at constructing stage could be based on technologies described in [13] with further upgrade to engineering radiation model during NPP unit operation.

The technologies tested for decommissioning of the Kozloduy NPP power units [13] are considered relevant for use at unit 1 of the Leningrad NPP with the RBMK1000 reactor as part of decommissioning operations presented in [16].

According to the concept of decommissioning of units No. 1-4 of the Leningrad NPP [17] optimistic forecasts, the work (including site survey and drawing up a sanitary passport) can last almost until 2060.

So DT development for the unit 1 of the Leningrad NPP decommissioning is an actual and urgent task for effective management of decommissioning process via nearest 40 years and recordkeeping.

Proposed in [4] option for development of a DT for NPP unit based on MACS worth to be effective for application of DT-technology in parallel in both parties: Design company (Party \#1) and the Rosenergoatom Utility filial NPP unit (Party \#2). Development of Digital passport (DP) as one of the DT basic parts could be started from early design stage with step-by-step adding information gathered via all pre-operation stages as shown on Fig. 4.

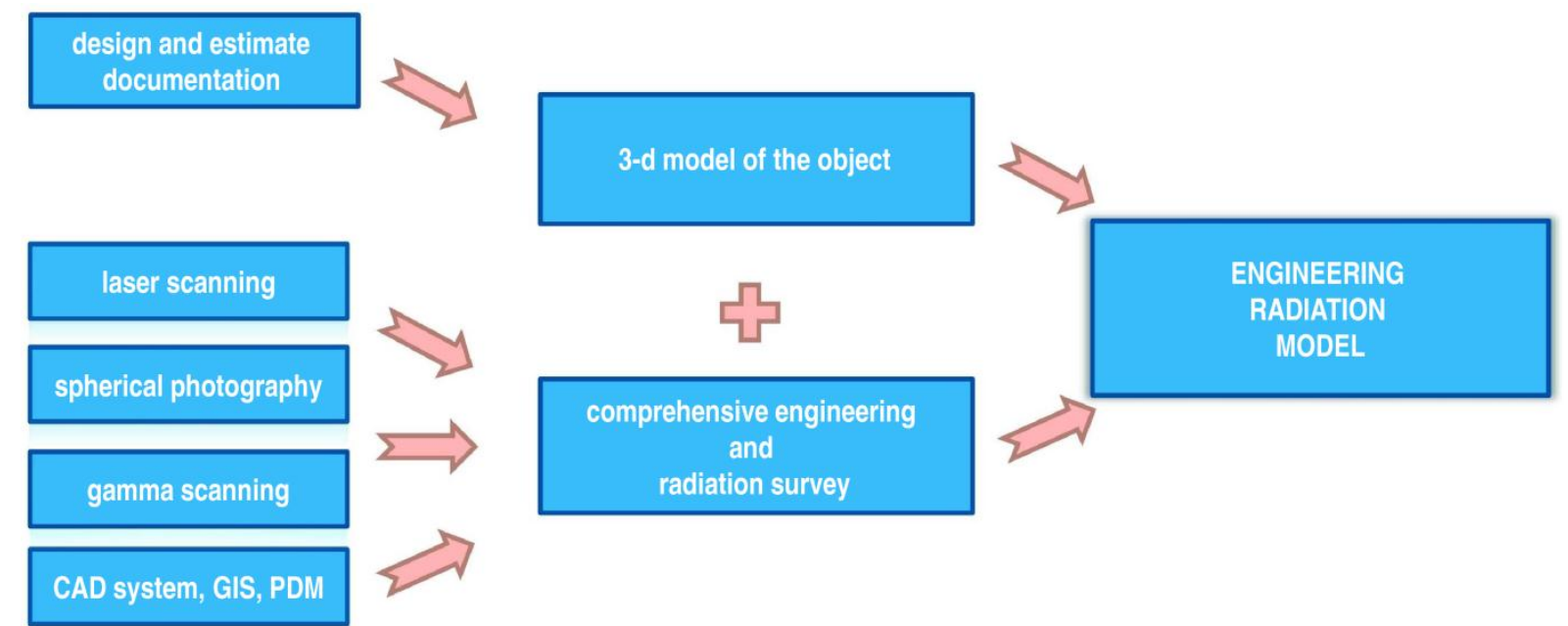

Fig.3. Assembly diagram of an engineering radiation model 


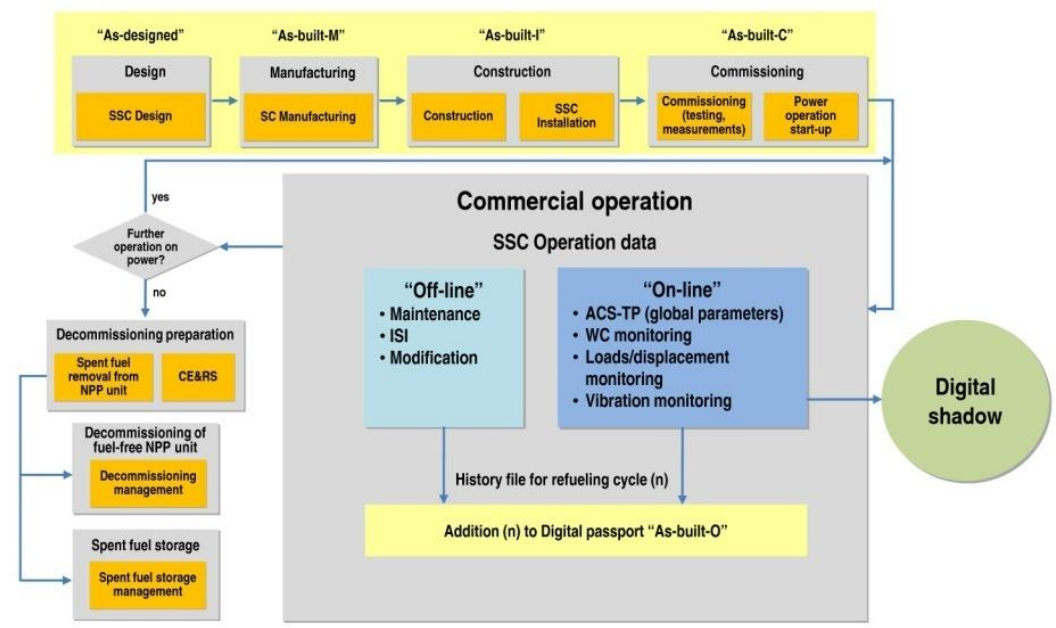

Fig.4. Processes of design, construction and operation of NPP unit related DT technology application

Mutual information exchange between Parties 1 and 2 provides both sides of the interaction with reliable and up-to-date information "as built" at all stages of the NPP life cycle (Fig. 5).

General designer of NPP site is responsible for development of final safety analysis report for "as-built" NPP Unit condition before starting commercial operation. So this company worth to be nominated as Task Leader from Party \#1.

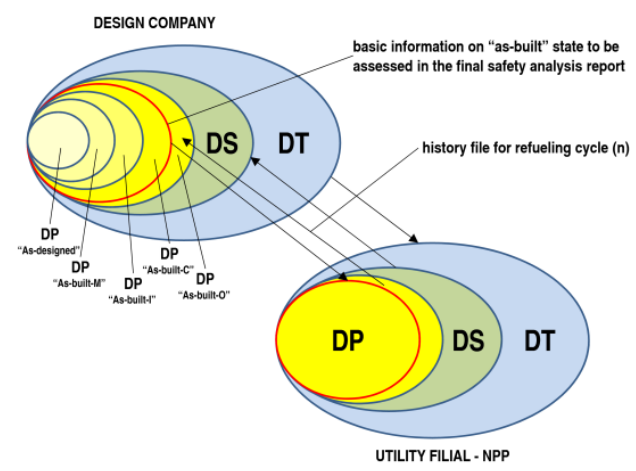

Fig.5. Preliminary scheme of information interaction in parallel application of DT technology by two parties (DP - digital passport; DS - digital shadow)

DT Digital Shadow (DS) gains on-line input information from NPP unit Technologic Process automated control system (ACS-TP) and local monitoring/diagnostic systems as shown on Figure 4.

DS role is to provide actual information for NPP operational personnel about deviations in SSC operation from design parameters and to supply DT prognostic module (implemented into DT shell) by on-line data.

Finally DT prognostic module can be used for different kind of operation trend assessment and NPP staff medium-term predictions for example on remaining life assessment of critical SSC (Fig. 6).

DT gives also possibility to predict obligatory (minimum required) scope of SSC maintenance during upcoming NPP outage within the NPP staff maintenance conception (as for example RCM (Reliability Centered Maintenance) according to [18-19]) taking into account level of specific SSC failure influence on NPP safety [20] and availability [21]. Optimization of periodicity of safety system testing based on procedure [22] could also be a benefit for NPP staff from DT application.

The proposed approach based on DT application can be an effective means of authoring the designer support for NPP staff at all stages of the life cycle, for example, when developing periodic safety reports prescribed in national regulatory documents [23-24].

Early application of DT technology helps to collect to collect comprehensive data on SSC condition which is important for preparation of NPP unit decommissioning stage. Such approach helps to optimise time and labor costs for implementation of final comprehensive engineering and radiation survey (CE\&RS) as shown on Fig. 4.

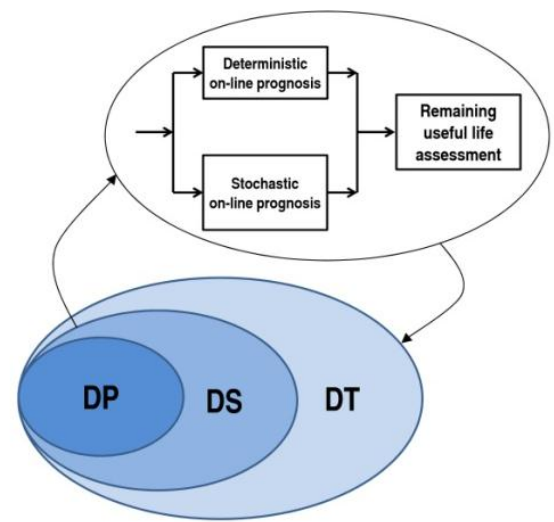

Fig.6. Scheme of interaction between DS and the predictive module in DT-shell for actual SSC remaining life assessment)

\section{Conclusion}

Finally it could be stated that proposed DT technology is effective for NPP units at all stages of life cycle.

Information exchange interfaces between the DTprototype (Party \#1) and the real DT (Party \#2) can provide the most adequate forecasts for the implementation of optimal maintenance strategies.

DT is an effective tool for NPP comprehensive data collection, management and recordkeeping during longterm operation. 
DT application is of high importance at unit 1 of Leningrad NPP with RBMK-1000 at early stage of preparation to decommissioning in order exclude any loss of valuable information due to use of obsolete big data handling technology.

The reported study was funded by RFBR according to the research project № 19-07-00455.

\section{References}

1. IAEA Safety Glossary. Terminology Used in Nuclear Safety and Radiation Protection (2019)

2. IAEA. Plant life management models for long term operation of Nuclear Power Plants. IAEA NUCLEAR ENERGY SERIES No. NP-T-3.18 (2015).

3. IAEA Safety Standards. Ageing Management and Development of a Programme for Long Term Operation of Nuclear Power Plants. Specific Safety Guide No. SSG-48 (2018)

4. M.I. Antonov, A.I. Arzhaev, K.A. Arzhaev, I.N. Denisov, A.A. Kalyutik, Yu.E. Karyakin, V.O. Makhanev, About the digital twin of a nuclear power plant unit in the framework of life time management, Proceedings of the International scientific and practical conference "Modern technologies and energy economics (MTEE-2020)", (2020)

5. A.V. Shutikov, Near-Future Plans of Rosenergoatom on Implementation of the Nuclear Power Development Strategy, Proceedings of the 11th International scientific and technical conference "Safety, efficiency and economics of nuclear power industry", (2018)

6. K.-S. Kang, Assessment of incidents experienced in power plant piping caused by FAC, IAEA Technical Meeting on Leak Before Break Concept and Application of Nuclear Power Plants, (2006)

7. IAEA. Proactive management of ageing for Nuclear Power Plants. SRS-62 (2009)

8. IAEA. Handbook on Ageing Management for Nuclear Power Plants. IAEA NUCLEAR ENERGY SERIES No. NP-T-3.24 (2017)

9. Ageing Management for Nuclear Power Plants: International Generic Ageing Lessons Learned (IGALL), Safety Reports Series No.82, (2015)

10. M.I. Antonov, A.I. Arzhaev, A.A. Arzhaev, K.A. Atzhaev, A.A. Kalyutik, Yu.E. Karyakin, V.O. Makhanev, Current issues of ensuring the integrity of pipelines and equipment's vessels of nuclear power plants, Proceedings of the International scientific and practical conference "Modern technologies and energy economics" (2019)

11. The Right to conclude a contract to perform design and survey work on the construction and modernization of nuclear power plants on the topic: "Development of an automated enterprise management system (AEMS) (including LAN) LNPP-2" (2014).

12. A.M. Reberger, A.A. Mets, Informational Support to Capital Construction Processes, Eleventh International Scientific and Technical Conference "Safety, efficiency and economics of nuclear power industry (MNTK-2018)", (2018)

13. D.A. Valov, Decommissioning of nuclear and radiation-hazardous facilities based on digital technologies, Presentation on III Intersectoral Information Technology Forum "Multidimensional Russia 2018”, (2018)

14. A.I. Arzhaev, V.A. Durynin, A.I. Ivanov, V.O. Makhanev, V.V. Meyer, A.A. Pavlovich, M.A. Podlatov, A.N. Razygraev, N.P. Razygraev, V.V. Rogozhkin, V.A. Zholobov, Support of design service life of NPP equipment and pipelines in longterm operation conditions, Ninth International Scientific and Technical Conference "Safety, efficiency and economics of nuclear power industry (MNTK-2014)", (2014)

15. Russia will build four new nuclear power units available at https://strana-rosatom.ru/2020/06/26/ $\%$ D0\%B2-\%D1\%80\%D0\%BE\%D1\%81\%D1\%81 $\% \mathrm{D} 0 \% \mathrm{~B} 8 \% \mathrm{D} 0 \% \mathrm{~B} 8-\% \mathrm{D} 0 \% \mathrm{~B} 1 \% \mathrm{D} 1 \% 83 \% \mathrm{D} 0 \% \mathrm{~B} 4$ $\% \mathrm{D} 1 \% 83 \% \mathrm{D} 1 \% 82-\% \mathrm{D} 0 \% \mathrm{BF} \% \mathrm{D} 0 \% \mathrm{BE} \% \mathrm{D} 1 \% 81$ $\% \mathrm{D} 1 \% 82 \% \mathrm{D} 1 \% 80 \% \mathrm{D} 0 \% \mathrm{BE} \% \mathrm{D} 0 \% \mathrm{~B} 5 \% \mathrm{D} 0 \% \mathrm{BD} \%$ D1\%8B-\%D1\%87\%D0\%B5\%D1\%82\%D1\%8B\% D1\%80\%D0\%B5-\%D0\%BD\%D0\%BE\%D0\%B2 $\% \mathrm{D} 1 \% 8 \mathrm{~B} \% \mathrm{D} 1 \% 85 /$.

16. A. Ananyev, V. Zimin, I. Korneev, Planning of Leningrad NPP's units decommissioning, Presentation on International Conference on Decommissioning of Nuclear Installations: Strategies, Practices and Challenges (AtomEco 2015), (2015)

17. Concern Rosenergoatom. Concept of Leningrad NPP's units with RBMK-1000 decommissioning, (2015)

18. GOST R 27.606-2013. Dependability in technics. Dependability management. Reliability centred maintenance.

19. IAEA. Application of Reliability Centered Maintenance to Optimize Operation and Maintenance in Nuclear Power Plants. TECDOC 1590, (2007)

20. STO 8841271.058-2017. Methods of substantiation of safety classes of systems and elements of nuclear power plants, (2017)

21. G.A. Ershov, V.V. Gurin, F.V. Nikolaev, O.G. Chaban, V.B. Morozov, Yu.V. Shvyryaev, Methodology for NPP Readiness Analysis, Eleventh International Scientific and Technical Conference "Safety, efficiency and economics of nuclear power industry (MNTK-2018)", (2018)

22. G.A. Ershov, V.V. Gurin, F.V. Nikolaev, O.G. Chaban, Procedure for substantiation of periodicity of planned checks of safety systems at nuclear power plants, Eleventh International Scientific and 
Technical Conference "Safety, efficiency and economics of nuclear power industry (MNTK2018)", (2018)

23. NP-001-15. General Safety Provisions for Nuclear Power Plants.

24. NP-006-16. Requirements to the Contents of Safety Analysis Report for a Nuclear Power Plant with VVER-type Reactor. 